\title{
Recall Urticaria: Aspirin Also Induces It
}

Cimbollek S, Ávila-Castellano MR, Labella M, Baynova K, Aramburu T, Quiralte J

Department of Allergy, Hospital Universitario Virgen del Rocio, Seville, Spain

J Investig Allergol Clin Immunol 2018; Vol. 28(2): 131-132 doi: 10.18176/jiaci.0219

Key words: Recall urticaria. Aspirin.

Palabras clave: Urticaria de recuerdo. Aspirina.

Recall urticaria (RU) is a rare biological phenomenon characterized by hives only at the previously injected site when the patient is re-exposed from another source [1]. The most common example is that of patients who have previously received subcutaneous allergen immunotherapy (scAIT) and present focal skin reaction at the sites of previous allergen injections when a new allergen is administered or after marked environmental exposure to the allergen $[1,2]$. However, other stimuli such as foods [1] and drugs (eg, heparin [3,4] and levofloxacin [5]) have been involved.

We present a case of RU caused by nonsteroidal antiinflammatory drugs (NSAIDs) in a patient who had previously received scAIT.

A 30-year-old woman with allergic rhinitis underwent scAIT to house dust mite (Depigoid Dermatophagoides pteronyssinus and Glycyphagus domesticus, Leti Lab) without incident. Complete tolerance to the maintenance dose was achieved without local reactions. Two years after discontinuation of scAIT, the patient experienced a local urticarial reaction with multiple hives at the previous injection sites 40 minutes after intake of $600 \mathrm{mg}$ of ibuprofen. These symptoms recurred on at least 7 occasions when the patient was exposed to ibuprofen (5) and metamizole (2). The patient tolerated paracetamol without adverse effects.

A single-blind, placebo-controlled oral challenge with ibuprofen $600 \mathrm{mg}$ was performed and elicited multiples hives
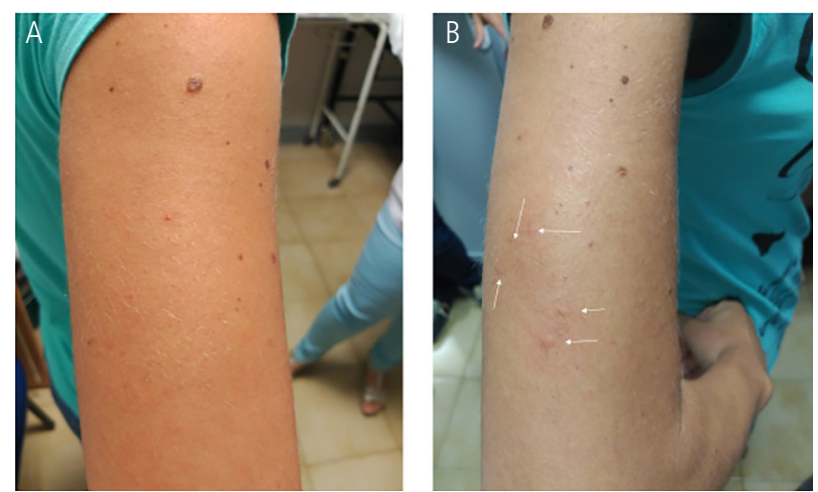

Figure. Clinical result of single-blind, placebo-controlled oral challenge with aspirin. A, Injection site before the challenge. B, Focal hives (white arrows) after challenge with a 300-mg dose. 
over a well-defined area on both arms. A subsequent singleblind, placebo-controlled oral challenge with aspirin revealed the same reaction (Figure), although a controlled challenge with celecoxib was negative.

In the patient we report, the symptoms were elicited by various NSAIDs (ibuprofen, metamizole, and aspirin) and resembled the pattern of patients with a cross-reactive cutaneous phenotype of sensitivity to NSAIDs [6]. This observation suggests that the enzymatic inhibition of the cyclooxygenase type I isoform could play a role in the development of this specific reaction. The tolerance of highly selective cyclooxygenase type 2 inhibitors such as celecoxib in the present case reinforces this hypothesis. However, the nature of the relationship between $\mathrm{COX}-1$ inhibition and the local immunological trace of mite remains largely unknown.

To our knowledge, this is the first report of recall urticaria after scAIT that was elicited with various NSAIDs. This phenomenon might be a new cutaneous subphenotype of cutaneous NSAID hypersensitivity in patients with respiratory allergy treated with scAIT.

\section{Funding}

The authors declare that no funding was received for the present study.

\section{Conflicts of Interest}

The authors declare that they have no conflicts of interest.

\section{References}

1. Karaayvaz M, Ozangüç N. Recall urticaria: a case report. J Allergy Clin Immunol. 1996;97:1419-20.

2. Ta $V$, White AA. An unusual case of recurrent "recall urticaria" in a patient on immunotherapy. J Allergy Clin Immunol Pract. 2014;2:459-60.

3. Caliskaner Z, Karaayvaz M, Ostürk S. Recurrent urticaria lesions in a heparin-allergic patient: Most likely another form of "recall urticaria". J Invest Allergol Clin Immunol. 2005; 15:78-80.

4. Weber HO, Fischer J, Kneilling M, Caroli U, Rocken M, Biedermann T. Recall urticaria induced by skin tests with heparin. Br J Dermatol. 2009;161:187-9.

5. Tan C, Zhu WY, Min ZS. Recall urticarial related to levofloxacin. J Eur Acad Dermatol Venereol. 2008;22:616-7.

6. Quiralte J, Blanco C, Delgado J, Ortega N, Alcántara M, Castillo $\mathrm{R}$, et al. Challenge-based clinical patterns of 223 Spanish patients with nonsteroidal anti-inflammatory-drug induced reactions. J Investig Allergol Clin Immunol. 2007;17:182-8.

Manuscript received July 26, 2017; accepted for publication November 30, 2017.

Joaquin Quiralte

Department of Allergy

Hospital Universitario Virgen del Rocío

Av Manuel Siurot $s / n$

41013 Seville, Spain

E-mail: joaquinquiralte@gmail.com 